This item was submitted to Loughborough's Research Repository by the author.

Items in Figshare are protected by copyright, with all rights reserved, unless otherwise indicated.

\title{
Rethinking the relationship between pedagogy, technology and learning in health and physical education
}

PLEASE CITE THE PUBLISHED VERSION

http://dx.doi.org/10.1080/13573322.2016.1226792

\section{PUBLISHER}

(C) Taylor \& Francis

\section{VERSION}

AM (Accepted Manuscript)

\section{PUBLISHER STATEMENT}

This work is made available according to the conditions of the Creative Commons Attribution-NonCommercialNoDerivatives 4.0 International (CC BY-NC-ND 4.0) licence. Full details of this licence are available at: https://creativecommons.org/licenses/by-nc-nd/4.0/

\section{LICENCE}

CC BY-NC-ND 4.0

\section{REPOSITORY RECORD}

Casey, Ashley, Victoria A. Goodyear, and Kathleen Armour. 2019. "Rethinking the Relationship Between Pedagogy, Technology and Learning in Health and Physical Education". figshare. https://hdl.handle.net/2134/22366. 
1 Rethinking the relationship between pedagogy, technology and learning in health

2 and physical education

3 Ashley Casey ${ }^{12}$, Victoria A. Goodyear ${ }^{3}$ and Kathleen M. Armour ${ }^{3}$

$4 \quad{ }^{1}$ Loughborough University, UK

$5 \quad 2$ University of Limerick, Ire

$6 \quad{ }^{3}$ University of Birmingham

7

8

9 Corresponding Author:

10 Dr Ashley Casey,

11 School of Sport, Exercise and Health Sciences,

12 Loughborough University,

13 Loughborough,

14 LE11 3TU,

15 UK.

16 Email: A.J.B.Casey@lboro.ac.uk

17 
18 Abstract: This paper seeks to address two key questions: 1) how could a pedagogically-driven approach to the use of DigiTech in HPE benefit young people's learning; and 2) what steps are required to develop new DigiTech pedagogies? The

21 paper is a response to the largely pessimistic views presented in this journal by Gard,

22 Lupton and Williamson about the role of technology in Health and physical Education

23 (HPE). In this paper, we argue that while we need to be aware of the risks, we also need to explore the opportunities for digital technologies (DigiTech) to shape HPE in new and positive ways. Specifically, we argue that a focus on pedagogy is largely missing from earlier discussions. In mapping the evidence base on DigiTech against a

27 three dimensional categorization of pedagogy - in the form of learners and learning, 28 teachers and teaching, and knowledge and context (Armour, 2011) - we are able to 29 demonstrate the value of a pedagogically-informed debate on this topic. The paper concludes by arguing for a 'profession-wide' debate to co-construct, trial and evaluate new ways in which we should - and should not - use DigiTech to optimise young people’s learning in HPE.

33 Practices, Digital Learning 
The use of technology in education should now be seen as a significant issue for everyone with a stake in education

(Selwyn, 2014, p. 1)

\section{The deployment of digital technology (henceforth called DigiTech) to support} learning has grown exponentially in recent years. This has led to increased critical scrutiny in a number of subject areas and from different disciplinary perspectives. In this context, it has been argued that developing a critically informed view of DigiTech in education is particularly important given the prevalence of impassioned, enthusiastic and, in the words of Neil Selwyn (2015, p. X), "bullshit” talk that has grown around it. The physical education (or, for the purposes of this paper, Health and Physical Education (HPE)) community has also engaged in these debates. The leading journal Sport, Education and Society, for example, recently devoted space for a discussion about the future of technology in HPE. In particular, Michael Gard, Deborah Lupton and Ben Williamson have raised new, if somewhat pessimistic, questions in this discursive space and these have provided one of the conceptual platforms for this paper. Drawing upon contemporary literature and our own recent work on this topic, the purpose of this paper is to rethink the links between pedagogy, technology and education. Specifically, while acknowledging the power and importance of the largely negative and alarmist views that have prevailed in our academic literature to date, we offer a different view that considers the value that a pedagogically-driven approach to the use of DigiTech in HPE could offer to support young people’s learning in a digital age. 
young people's learning; and 2) what steps are required to develop new DigiTech pedagogies? First, we provide a brief overview of Gard, Lupton and Williamson's arguments. Second, drawing on existing knowledge, we consider the relationship between DigiTech and pedagogy using a three dimensional categorisation of pedagogy. Third we make the case for the potential benefits of building new links between DigiTech and pedagogy in HPE and consider the 'what next?' question. In particular, we seek to mobilise the HPE profession, including both practitioners and researchers, to engage in a 'profession-wide' debate to co-construct, trial and evaluate new ways in which we should - and should not - use DigiTech to optimise young people's learning in HPE.

\section{Gard, Lupton and Williamson - an overview}

Gard (2014) introduced the concept of 'eHPE', which he defined as HPE’s “ongoing investment in public health” and “digital technology” (p.828). Gard’s argument about DigiTech is grounded in his longstanding critique of the presumed link between physical education and health, and the subsequent claims HPE scholars have made about the role DigiTech will play in helping HPE improve health (c.f. McKenzie and Lounsbery, 2013). Gard (2014) claims that DigiTech will intensify negative discourses of and related practices in "measurability, accountability, performativity and standardization” (p. 833). As a result, Gard argued that HPE will promote "the punitive, judgemental, time-consuming, intellectually arid and potentially unhealthy surveillance of [young people's] bodies and behaviour” (p. 835). HPE, in Gard's view, will be forced into a world that thinks "being healthy is a simple matter of being told, adopting and repeating a set of easily describe behaviours” (p. 839). 
risk of being replaced by health-related DigiTech. In other words, the perceived capabilities of DigiTech could further endorse societal, economic and politically supported discourses of performativity in education (see Evans, 2013; Apple, 2007), meaning that teachers no longer have their traditional role in promoting physical activity and health.

Similar to Gard, Lupton (2015) was pessimistic about the role of teachers in HPE as a result of the growth of DigiTech in education. Lupton (2015), however, was particularly concerned about the dangers of DigiTech leading to a whole school approach to data-led surveillance of each individual child. Lupton (2015, p. 126) suggested that the proliferation of health promotion and fitness apps and self-tracking devices means that it is only a matter of time before "the ethos and practices of selfresponsibility" come to represent "key forces in behaviour change” for young people in HPE. Drawing on her own typology of five modes of self-tracking (see Lupton, 2014), Lupton (2015) challenged the reader to consider how long it will be before 'private’ self-tracking becomes ‘communal’ (i.e. in a class), 'pushed’ (i.e. teacher initiated), 'imposed' (i.e. health interventions), and 'exploited' (i.e. used for the purposes of others). Consequently, Lupton (2015, p. 127) posed a controversial question about the likelihood of reaching a situation where "students are forced to wear heart-rate monitors to demonstrate that they are conforming to the exertions demanded of them by the HPE teacher?” Nevertheless, it is also possible to argue for another more positive way of viewing this issue. Other subject areas in the school curriculum, including Maths, English and Science, are making extensive use of learners’ data to drive more personalised forms of learning (see Apple, 2007). Perhaps it is possible to argue for new pedagogically-appropriate futures for HPE based on the use of individuals' health and fitness data? We will return to this issue later. 
113 DigiTech in education, arguing that wearable technologies ${ }^{1}$ will eventually control

114 and govern the educational process. In this scenario, Williamson (2015, p. 135)

115 claimed that HPE could become a site where the use of existing DigiTech such as

116 "fitness testing, movement analysis software, kinetic videogaming and digital

117 pedometers" (Williamson, 2015, p. 135) will be replaced by an "algorithmic skin”

118 (p.133). This skin was defined as "an artificial informational membrane that

119 continually interacts with, and is activated by, a densely coded informational

120 environment” (ibid, p. 148). As a result, Williamson predicted that commercially

121 produced DigiTech will begin to govern the educational process because of its

122 capabilities to produce 'evidence-based' results. Here again, however, a counter view

123 might be that - at the very least - such results are based on real rather than proxy and

124 rather unreliable or self-reporting evidence. Through an algorithmic skin teachers

125 could access new forms of evidence about young people’s physical activity levels.

126 Comparably to Sandaña (2014, p.4) we might argue that such "data is a gift, so be

127 thankful when it is given to you".

128 In summary, Gard, Lupton and Williamson have outlined ways in which a

129 data-driven society - exaggerated by the use of DigiTech- could lead to levels of body

130 surveillance that are unintended, unimagined and/or untested. This is a future for HPE

131 that seems to bypass teachers. In other words, DigiTech could ultimately deprive

132 teachers of the opportunity and capability to teach. Yet, how realistic - or indeed

133 unduly pessimistic - are these dystopian views?

134 The three authors made little attempt to ground their arguments in the

135 evidence base on (i) what kinds of DigiTech young people and their teachers use

\footnotetext{
${ }^{1}$ Wearable technologies are variously described as "self-tracking, personal informatics, personal analytics or technologies of the 'quantified self'” (Williamson, 2015, p. 134).
} 
currently in and beyond formal HPE settings; (ii) teachers' and young people's contemporary views on DigiTech; and (iii) the pedagogical implications of the wider physical, social, and economic architectures of schools and classrooms that support technology-mediated teaching and learning. In other words, it seems that what is missing in their arguments is a focus on the potential for new pedagogies of DigiTech; for example, current or imagined links between pedagogy and DigiTech that could work to enhance or even ‘accelerate’ (Fullan, 2013a) young people’s learning in HPE. In the next section, therefore, we use a three dimensional concept of pedagogy as a framework for addressing our first question: how could a pedagogically-driven approach to the use of DigiTech in HPE benefit young people's learning?

\section{The pedagogies of DigiTech in HPE}

Pedagogy is a complex and slippery concept with a range of definitions (see Dron, 2014). Nonetheless, a widely adopted conceptualisation in physical education and sport pedagogy is that pedagogy is the connection between three dimensions, (i) learners and their learning, (ii) teachers and their teaching and (iii) knowledge in context (Armour, 2011; Quennerstedt et al., 2016). As Armour (2011, p.14) put it: “the key point to grasp about any pedagogical encounter between teacher/coach and young learner is that all three dimensions of pedagogy are present and interacting”. In this categorisation of pedagogy, the learners/learning dimension "foregrounds children and young people as diverse learners and the ways in which they can be supported to learn effectively” (Ibid, 2011, p.13); the teachers/teaching dimension positions teachers as lifelong learners “who continuously and critically reflect upon their personal capabilities to meet the needs of young learners” (ibid, p.14); while 
161 knowledge/context refers to the value that is placed on what is selected to be taught or

162 learnt and the contingent contextual factors. But, how does a focus on the three

163 dimensions of pedagogy shed new light on the potential of DigiTech to support

164 learning in and beyond HPE?

165 Learners and learning

166 In 2016, teachers and other educators are faced with a generation of young learners

167 who identify with selfies, hashtags, and emojis, and who see sharing, liking, tweeting,

168 blogging and vlogging as everyday practices (Rich \& Miah, 2014; Selwyn \& Stirling,

169 2016; Tom, 2012). Digital devices, applications (apps ${ }^{2}$ ) and social networking sites

170 are readily accessible and are used by many young people on a daily basis (Greenhow

171 \& Lewin, 2016; Lenhart, 2015). It has been estimated, for example, that 71\% of

172 American adolescents use the social networking site 'Facebook' as a platform for

173 communication (Lenhart, 2015). This use of social media by adolescents is, perhaps,

174 unsurprising given that:

175 i) Children begin web 'surfing' and accessing social media from as young as age

176 four (Taranto et al., 2011);

177 ii) Young people are being deliberately targeted as consumers of DigiTech

178 (Williamson, 2015; Öhman et al., 2014); and

179 iii) DigiTech is accessible to a wide range of youth in diverse socio-economic

$180 \quad$ contexts (Greenhow \& Lewin, 2016).

181 The seemingly unstoppable growth in young people's engagement with DigiTech in

182 their personal lives (Rosen, 2010; Selwyn \& Stirling, 2016) means that these

183 technologies are socially and culturally relevant. Although, as Rosen (2010) suggests,

184 the social relevance of DigiTech could act as a type of leverage to engage young

\footnotetext{
${ }^{2}$ An application programme is a computer programme designed to perform a group of coordinated functions, tasks, or activities for the benefit of the user
} 
people in learning, there are significant risks to young learners and on this point we agree with the arguments of Gard, Lupton and Williamson. Health-related - extending to medical - DigiTech has the potential to have a profound positive or negative impact on young people’s learning about health, physical activity and the body, both within and outside of formal education experiences. On the negative side of the argument, the social construction of particular body ideals is evident in the popular practice of taking and posting 'selfies' (Miguel, 2016; Warfield et al., 2016). Extending 'old media’, selfies exaggerate the self-presentation of filtered, gendered, ideal and 'perfect' bodies because they are socially constructed, actualized and re-enforced through online networks (Warfield et al., 2016). This is a particular concern when a connection is made between the images presented and shared in selfies and presumptions made about ‘health' (see, for example, healthyselfies.org) and, what we might term, un-healthy selfies. Further illuminating the concerns raised about 'teen magazines' and 'size 0' discourses (Kerner, 2013), there is evidence that young people are using selfies as a communication mechanism through which to engage with specific groups and that this acts to reinforce un-healthy discourses and behaviours (see \#thinkspiration on Twitter as an example). What we can conclude from these examples is that the rise of 'healthism' (an ideological, neo-liberal and public construct of health) in adults, and concerns about individual autonomy, self-monitoring and obsession/addiction seen in social media (Lupton, 2015) are also growing concerns for youth (Rich \& Miah, 2014).

Further risks arise from the extensive digital footprints that young people are creating and, as is the case of in HPE, the digital footprints teachers might be encouraging young people to create. Halford (2016), for example, raised questions 
about what is considered public or private on social media sites. In challenging what

211 might be considered 'private', Halford (2016) suggested that a person, a company or

212 even the host site (e.g. Facebook) are able to access the digital data, regardless of

213 privacy protection plans, guidelines, and regulations. The HPE profession must

214 consider, therefore, whether digital images, and personal data about the body and/or a

215 child's health generated in HPE lessons could and should be accessible to others

216 outside of the education content.

Yet, there is another way of looking at learners and learning and DigiTech in

218 HPE. For example, as seen in other educational contexts (see Greenhow \& Lewin,

219 2016), there is significant potential for teachers to connect young people’s uses of

220 DigiTech with their learning experiences in HPE. Indeed, because DigiTech already

221 provides an accessible and potentially rich resource for learning about health, physical

222 activity and the body, it could also provide a useful resource for teachers to construct

223 and deliver forms of knowledge to young people in ways that are engaging,

224 immediate and attractive (Casey, Goodyear \& Armour, 2016). Calls from political,

225 research and practice fields certainly seem to support such a view, highlighting the

226 urgent need to understand how technologies can support young people’s learning in

227 optimal ways (Fullan, 2013a; DCMS, 2015; UNESCO, 2015; Kong et al., 2014). It is

228 certainly safe to assume that DigiTech will influence young people's learning about

229 physical activity and health regardless of the position a teacher takes on the matter.

230 There is clearly a need, therefore, for further critical, informed and profession-wide

231 debate around the rise of 'healthism' and the ethical issues of DigiTech and what this

232 means for learners and their learning. In line with Gard, Lupton and Williamson, we

233 agree that it is unacceptable to 'glorify' the capacity of DigiTech to educate, and yet

234 to be unaware (or plead ignorance) of the implications; for example, the ethical 
235 challenges posed by public data. The prevalence of DigiTech in the lives of young

236 people, however, means that teachers cannot simply ignore the dangers whilst

237 simultaneously grasping the opportunities of DigiTech. So what is the evidence on

238 teachers' views on and uses of DigiTech in HPE?

239 Teachers and teaching

240 Any debate about the role of DigiTech in HPE must have a focus on the role

241 of teachers given the arguments that teachers have the greatest impact on students and

242 their learning (Hargreaves \& Fullan, 2012; Hattie, 2012, 2009). When compared to,

243 for example, the school context, parents, home, resources, or the quality of a school's

244 leadership, it is consistently argued that teachers are highly influential (Apple, 2007)

245 and should be placed at the forefront of reform efforts to improve education

246 (Hargreaves \& Fullan, 2012; Hattie, 2012, 2009). Clark (1995, p.3), for example,

247 argued that "teachers are the human point of contact with students. All other

248 influences on the quality of education are mediated by who the teacher is and what the

249 teacher does”. Developing a knowledge-base about what teachers learn, do and

250 practise is, therefore, vital for the creation of effective and contemporary policies,

251 programmes and practices (Cordingly et al., 2015; Hattie, 2009). Yet, what teachers

252 think, say, and do with DigiTech has received rather little consideration.

While DigiTech is celebrated for its "astounding and abounding creativity”

254 (Fullan, 2013a, p.36), it has been argued that innovation in its use in education has

255 stagnated (Apple, 2006; Robinson, 2011). Few teachers are able to incorporate

256 DigiTech into the pedagogical context in purposeful ways that extend pedagogical

257 capacity (see Fullan, 2013a). While there is much talk about how the latest 'gizmos

258 and gadgets’ could leverage young people’s learning (Rosen, 2010), and the ways in

259 which 'big' edu-businesses are focussed on designing and marketing educational 
260 DigiTech to ‘transform’ teaching and learning (Enright et al., 2016; Gard, 2014;

261 Lupton, 2015; Williamson, 2015), technology-mediated teaching and/or learning is

262 not a mainstream practice. Indeed, Fullan (2013a) among others (c.f. Hastie et al.,

263 2010; Palao et al., 2015; Selwyn, 2015), has argued that the use of DigiTech in

264 schools is "conspicuous by its absence or by its superficial, ad hoc use” (p.13).

265 Vrasidas (2014), similarly, reported that only 35\% of teachers use DigiTech in the

266 classroom, while Sipilä (2013) demonstrated that almost half of teachers feel under-

267 prepared to use DigiTech to support learning. In the context of HPE, Kretchmann’s

268 (2015) small-scale study in Germany indicated that half of teachers surveyed felt they

269 had enough experience to integrate DigiTech into HPE. Yet more than $80 \%$ of

270 teachers suggested that they did not have enough pedagogical knowledge and

271 experience of how integrate DigiTech effectively and that they wanted access to more

272 pedagogical scenarios that exemplified DigiTech use in HPE. Indeed, most teachers

273 expressed a preference for traditional technology (i.e. images and blackboards), rather

274 than, for example, more recent collaborative, user-focussed, and interactive

275 technologies, such as social media, apps, and 'mobile' devices.

276 The evidence-base on teachers, therefore, seems to suggest that while young

277 people are active users and consumers of DigiTech, teachers are resistant and they

278 struggle to integrate DigiTech in pedagogically sound or innovative ways. The

279 literature suggests that large numbers of teachers are either resistant or even 'Luddite'

280 in this regard. Drawing on the work of Webster and Robins (1986) and Bromley

281 (1998), Reid (2009) explored the usefulness of employing a Luddite analysis to

282 generate an understanding of resistance to technology in education. Reid (2009, p. 
283 290) suggested that Luddism ${ }^{3}$ was not a fight against technology per se but one

284 against "a particular kind of political economy and ideology...[which] changed the

285 traditional patterns of social life”. Reid argued firstly that Luddism served as a refusal

286 to isolate technology from social relations, and secondly that technological change

287 presented a threat to a particular kind of life. Common populist terms used today to

288 describe opposition or resistance to technologies or technological change include

289 'technophobe’, 'non-techie', 'dinosaur', 'fossil' and 'diehard'. The 'Luddite' question

290 arises, therefore: "what changes to the traditional patterns of social life are these

291 modern day Luddites raging against?”

It could be argued that, much like most existing continuing professional

293 development (CPD) experiences (Cordingly et al., 2015), the CPD mechanisms to

294 support teachers in using DigiTech in new and pedagogically appropriate ways has

295 been either absent or ineffective. As a result, DigiTech use is driven by so called

296 'early-adopters'; innovative, passionate and enthusiastic teachers who are inspired by

297 their personal interest in technologies and their belief that DigiTech can enhance

298 young people’s learning (Casey et al., 2016). The lack of high quality CPD is a

299 problem for these early adopters (lack of critical challenge) as much as it is for the

300 wider Luddite teacher population (lack of knowledge and confidence). Equally, and as

301 we will discuss in the next section, school and classroom contexts are not always

302 conducive to DigiTech use. A lack of support within the local context has long been

303 regarded as a powerful mediating factor in inhibiting teachers' attempts to change,

304 learn and develop (Fullan, 2015) either with or without CPD mechanisms in place.

305 Perhaps the most effective form of CPD in HPE we could imagine would be where

306 early adopters and Luddites were able to work together within a three-dimensional

\footnotetext{
${ }^{3}$ A member of any of the various bands of workers in England (1811-16) organized to destroy manufacturing machinery under the belief that its use diminished employment. (Dictionary.com)
} 
critical, pedagogical and analytical framework. The ambition would be to support both groups to challenge the views of the other, from the starting point that neither is

309 inherently 'correct'. This type of CPD activity is aligned with the concept of

310 'effective’ CPD as proposed by Armour, Quennerstedt, Chambers and Makopoulou

311 (2015) who argued for CPD that allows teachers to focus on complexity, addresses

312 contemporary challenges, bridges research and practice, and nurtures their career-long

313 growth as learners. Yet, as numerous PE-CPD studies have reported (see Parker \&

314 Patton, in press) few such opportunities are available. It is difficult to imagine,

315 therefore, how HPE teachers (early adopters and Luddites alike) can currently have

316 the kinds of structured discussions that would support them to use DigiTech in

317 pedagogically sound ways.

$318 \quad$ Knowledge in Context

319 In education systems, the "knowledge to be taught, coached or learnt is always a

320 context-bound decision that reflects, reinforces, reproduces (and sometimes

321 challenges) what powerful individuals or groups believes is valuable at any given

322 time” (Armour, 2011, p.13). Considering this point in the case of DigiTech in HPE

323 raises a host of interesting questions about who is driving what. For example, the

324 wider societal context is one where there is an easy of access to mobile health apps;

325 indeed Lupton (2015) puts the figure at over 100,000 such apps available on major

326 app stores and this number is rising all the time. Meanwhile, in HPE, there is a close

327 alignment between the leading HPE physical activity/health discourses (see Gard,

328 2014) suggesting that DigiTech is already driving forms of knowledge that arise in

329 our HPE curricula on health and fitness. Yet, the implications of this trend appear not

330 to have been recognised in formal education policy (see DCMS, 2015 as an example).

331 Moreover, within the local context of schools and teachers' classrooms, there is little 
evidence of radical change and innovation driven by technology tools or devices. We do acknowledge that change has occurred i.e. in the expectations that teachers use technologies to provide further understanding of 'learning' in HPE and in the introduction and sustained use of DigiTech such as games analysis, Heart Rate Monitors, pedometers, apps in phones etc. That said, there is evidence to suggest that schools and teachers continue to value traditional sports skills and games (Kirk, 2010) or, in Nordic countries, dance/gymnastics and outdoor activities (Quennerstedt, 2008). Meanwhile, young people are living in a parallel world of DigiTech that promotes views on health and fitness that sometimes accord with - and also challenge - our traditional practices in HPE.

At the policy level, the contemporary National Curriculum and Standards operating in a number of countries agree that as a result of a highly effective PE programme, all pupils should be able to lead what they term 'healthy' or 'healthenhancing' lives. Yet, the small number of available analyses on the use of DigiTech in HPE suggests that the forms of knowledge promoted tend to reinforce historical knowledge patterns. For example, DigiTech has been used to promote knowledge about skills and games (see Sinelnikov, 2013) and dance (Öhman et al., 2014). While it has been argued that new models, methods and ‘innovative’ pedagogical strategies should shift learning away from a focus on specific activities in HPE (O’Sullivan, 2013), teachers' personal philosophies, training, and the school context all seem to act to reproduce the traditional activity focus (Kirk, 2010).

The pedagogical questions to be asked at this stage, therefore, are about the power of the context to adapt to, adopt or even shape new forms of knowledge that may or may not be positive. There is no doubt that DigiTech is opening up new possibilities and spaces in and through which to learn. If these spaces, however, 
continue to be constrained by data reporting, limited curriculum opportunities and traditional practices and outcomes, then the best result we can hope to achieve is slightly better solutions to the same problems (Robinson, 2011). Moreover, if teachers are unsupported by appropriate forms of CPD, they will either use DigiTech in essentially uncritical ways that are more informed by technology than pedagogy, or avoid it (Howard \& Mozejko, 2015). DigiTech is, after all, only as "good as the pedagogical methods it employs” (Ferster, 2014, p. 176).

\section{Summary}

Thus far, we have articulated an apparent disconnect between the debates on the use of DigiTech in education, and questions about pedagogy. Specifically, we have raised concerns about young people’s learning on health through DigiTech outside of the school context and the implications for teachers and teaching within the school context. We have echoed some of the pessimistic views of Gard, Lupton, and Williamson, while also suggesting that there might be alternative readings of the future of DigiTech in HPE.

In the next section, we challenge ourselves and the wider HPE profession to think differently about DigiTech in HPE and we answer our second question: what steps are required to develop new DigiTech pedagogies? We argue that we need to focus on a complex, multi-layered understanding of pedagogy; i.e. in those places where learning, teaching and context converge- to consider what might be possible for DigiTech in HPE. In other words, as a profession, we argue for the need to engage in 'blue skies' thinking and critical yet constructive dialogue to imagine new futures for HPE and the development of new - pedagogies supported by DigiTech - in driving radical change. 


\section{Section three: 3 . What steps are required to develop new DigiTech pedagogies?}

As the papers in Sport, Education and Society show, DigiTech in HPE is becoming an important facet of the wider discussions in our field. Yet, the works of Gard, Lupton and Williamson illustrate a curious lack of discussion about the role of pedagogy in the analyses of the role of DigiTech in HPE. In our recent book (see Casey et al., 2016) we set out to address this gap. The original aim was to consider a concept that Casey (2014) had identified as 'pedagogies of technology’ in HPE, as exemplified in thirteen pedagogical cases (Armour 2014) of teachers and their uses of DigiTech. The concept of pedagogies of technology was explained as follows:

Pedagogies of technology are critically aware and technically competent pedagogies that can be developed in practice to maximise the latent potential of technologies to accelerate learning in meaningful ways that meet the individual needs of diverse learners. The starting point for a pedagogy of technology is a desire to do things differently, rather than to do the same things using 'flashy' tools and gizmos.

(Casey el al., 2016, p.7)

Individual teachers at the heart of each case came from different countries, and the resulting pedagogical cases were similar in style to the original model developed by Armour (2014). The narrative at the heart of the cases centred on an HPE teacher/practitioner who uses DigiTech. From this starting point, analyses were undertaken by academics from different disciplines, including pedagogy and, for the purposes of CPD, the teacher/practitioner was asked to conclude the chapter with their reflection on the analysis.

So what did we learn? Firstly, a critical review of all the pedagogical cases suggested that the term 'pedagogies of technology' can indeed be helpful in 

pedagogically different with technology. At the same time, and echoing the evidence presented earlier, we concluded that we saw very little in the cases that was genuinely radical or innovative. So, although many practitioners and scholars have positioned

411 DigiTech as a kind of "supertool”, we were struck by the lack of new forms of

412 learning, different types of teaching, or indeed any alternative HPE contexts for 413 learning. What we saw instead was that DigiTech enabled teachers and students to do 414 the same things faster and more efficiently, albeit after some teachers had invested 415 time and effort in learning how to use different technologies. We were left wondering 416 whether what we saw in the cases was the limit of our imagination as a profession. Some extracts from the practitioner reflections in the pedagogical cases are illustrative. Firstly, some teachers were unable to use DigiTech optimally in their practice because there was much they had never had the opportunity to learn - or had even considered as a learning possibility. For example, Dylan reflected "I would be

421 interested in investigating the lived experience of students engaged in learning using 422 the iPad" (Goodyear et al, 2016, p. 26). James commented: "Even though I consider 423 myself a reflective practitioner, I had not connected my own professional journey to 424 developments in technology... I have been taken back by the accuracy of the analysis

425 from the academic experts and the amount of theory that highlights how and why 426 these processes occur” (Chambers et al, 2016, p. 63). In another case, Beatrice noted 427 that "in teaching it is important to take a critical look at pedagogies of technology and 428 not think all teaching problems can be solved by technological solutions

429 (Quennerstedt et al, 2016, p. 82) while Andy (Fletcher et al, 2016, p. 118) learnt that 430 changing his mind about using DigiTech in an area of his practice "should not be 431 looked at as a failure but as a strong example of sound pedagogical decision-making”. 
432 Indeed, the ambition to learn openly from 'mistakes' was a recurring theme. As was

433 noted earlier, some practitioners appear willing to invest significant amounts of time

434 in learning how to use and experiment with different forms of DigiTech, Joey is a

435 good example of this (Gleddie et al, 2016, p. 134) and he was clear that he would be

436 able to learn most effectively where he could share both his successes and his failures:

I often share the "best" or in other words the refined or rehearsed version of what actually happened in my class. I receive digital pats on the back for my success, but I do not necessarily grow as a teaching professional as a result. To do that, I need to share the things that did not go as well in lessons and discuss what might have been missed opportunities in my teaching. Secondly, following the practitioner narrative and the analysis from three different disciplinary perspectives, a pedagogy expert was tasked with locating the issues raised in a coherent pedagogical space. Pedagogues, however, struggled to do this in ways that opened up new and innovative pedagogical possibilities. For example, Castelli et al, (2016) drew on the established theories of problem-based

448 learning as an analytical framework, Jones et al, (2016) (amongst others) used TPACK, Enright et al (2016) focussed on the privatisation of physical education although they also include a section on 're-imagineering' HPE, and Armour et al 451 (2016) drew on narrative theory and Deweyian concepts. What we learnt through the process of constructing pedagogical cases, 453 therefore, is that defining pedagogies of technology was helpful in framing the task 454 for the pedagogical case author teams and encouraging them to think innovatively. 455 Yet, the cases revealed remarkably little practice that could be regarded as radical as a 456 direct result of using DigiTech to support learning. Instead, we have come to the 
conclusion that while DigiTech should be able to "deepen and accelerate learning” (Fullan, 2013b, p 28) and enable teachers to do things “differently”, we have missed out the prior-step of clarifying what is meant by “accelerating” learning in HPE, and doing things "differently". Essentially, the question for the profession is: what can we imagine for HPE?

Reflecting on the pedagogical cases process, we are able to offer a brief example of how an understanding of the benefits of DigiTech might be enhanced by pedagogical analysis. We draw again on the pedagogy framework of learners and learning, teachers and teaching and knowledge in context (Armour, 2011) mentioned earlier. In their pedagogical case chapter, Quennerstedt et al. (2016) used Armour’s framework to consider Béatrice’s use of dance video games in her teaching. Quennerstedt et al. (2016) argued, from a learners and learning perspective, that the key is not to consider how students are learning but what they are learning. They posed the question: "is the aim to learn different movement qualities, a particular dance, rhythm, dance moves, creativity, biomechanical or physiological principles? (Quennerstedt et al., 2016, p. 79). From this perspective, DigiTech is not a "gizmo" but a pedagogical intent to help learners learn. Secondly, in focussing on teachers and teaching, Quennerstedt et al. (2016) concluded that Béatrice used DigiTech as a teaching resource and emphatically not as a substitute teacher. Thus, the dance video game was described as "an instructor, a source of inspiration and a resource for students”(p. 79). In their consideration of context, Quennerstedt et al. (2016) challenged the reader to contemplate, from a cultural, historical and subject area perspective, why dance is taught at all; for example, is it "an activity, a cultural form, a form of exercise or an aesthetic practice and expression?” (p. 80). This level of analysis offers rich possibilities for teacher learning in CPD. 
claim that we need to open a profession-wide debate about the nature of radical pedagogies in HPE that make optimal use of the potential capacity of DigiTech while minimising the potential harms. Looking back to earlier sections of this paper, a useful starting point is Lupton’s (2015, p. 127) question: heart-rate monitors to demonstrate that they are conforming to the exertions demanded of them by the HPE teacher? An immediate reaction might be negative, given the dangers posed by a

491 growing focus on performativity as outlined by Gard (2014) and many others in our 492 field (Enright et al. 2016; Gleddie et al, 2016) and within education more broadly 493 (Apple, 2007). There might, however, be another response. In their individual and collective arguments about DigiTech, Gard, Lupton and 495 Williamson suggested that DigiTech could offer more personalised and individualised 496 learning opportunities. Building on this view, and using Lupton’s example above of 497 the heart rate monitor, we would like to argue that teachers could use DigiTech to 498 monitor and tailor 'physical exertions' to the individual student and that this might be 499 a very good thing. Indeed, it might be a better pedagogical strategy based on accurate 500 individualised data that allows teachers to better meet the needs of each student.

501 Although Gard, Lupton and Williamson suggested that such an approach could work 502 to drive school improvement to the exclusion of teachers, it could also be argued that 503 in the hands of skilful teachers, good data could be used to drive new and better forms 504 of learning in HPE. Certainly, Hattie (2012, 2009), among others (e.g., Dinham, 505 2013) have argued that teachers who have the greatest impact on learning are those 506 who can accurately diagnose and plan for the learning needs of their students. The 
better the quality of the information a teacher has about a student, the more effective their pedagogies are likely to be. From this perspective, DigiTech has the potential to be an invaluable pedagogical device to support learning in individually and developmentally appropriate ways.

The problem, at this stage, is that we have not had a grand profession-wide debate that could inform our decisions about the use of DigiTech in HPE and its potential to change our practices for the better. A 'profession-wide' debate is not one that can rage in the pages of academic journals read mainly by other academics (Sandaña, 2014). As Sandaña (2014) suggests, if we keep doing this we will keep recycling the message of, “I got a different way of lookin' at it”, and, in turn, the same pedagogical practices will most likely continue to exist. Instead, we 'all’ need to 'jump on' the enthusiasm that DigiTech has in young people’s lives and begin to coconstruct new and exciting futures for HPE.

A profession wide debate would involve policy makers, businesses, health professionals, technology experts, teachers, students, parents, and the wider community. In other words, anyone who is a participant in, or invested in HPE. We know from existing evidence-base that exercising the voices of all key stakeholders in HPE is a powerful mechanism for diagnosing learners' needs, evaluating teachers and teaching, co-constructing new contexts for learning and creating effective practices within HPE (see Leatherdale et al., 2015, and Luguetti et al., 2015). We have been sensitised to the dangers of DigiTech in HPE by the ground-breaking work of Gard, Lupton, and Williamson yet, at the same time, their pessimistic views are somewhat 'zoomed out' from the realities of young people's digital lives. We have learnt from the pedagogical cases process that new futures are possible for HPE, but that the collaborations we facilitated between academics and practitioners highlighted a lack 
532 of radical change in HPE. By opening these debates and questions about co-

533 constructing new forms of HPE within the social and cultural framework of DigiTech,

534 to a wider audience, however, we might generate discussions that can lead to

535 improvements to HPE.

536 We conclude this paper by drawing on Veletsianos (2016) to suggest that a

537 focus on "emerging technologies" and "emerging practices" in digital learning could

538 be a useful way forward. As Veletsianos (2016) argues, “emerging technologies” and

539 “emerging practices” transcend disciplines and, moreover, what makes practice and

540 technology emerging is not the technology, but rather the environments in which

541 technologies and practices operate. Emerging technologies and practices, therefore,

542 are foregrounded in the belief that technologies and practices shape and are shaped by

543 sociocultural environments. Another notable characteristic of emerging technologies

544 is that while there is significant potential for change, such potential has not yet been

545 realised. This final characteristic is the key message of this paper. The 'take home

546 message' we want to provide is that DigiTech crosses multiple sectors (e.g.,

547 education, journalism, sport), multiple contexts (e.g., home and school), and can be

548 used in multiple ways (e.g., improve learner-learner interaction or personalised

549 learning). As an academic profession, therefore, we will do our young learners a

550 disservice if we simply subscribe to a pessimistic view of the role of Digitech in HPE.

551 As Velestianos (2016) argues, DigiTech is not yet established in education. This

552 provides an opportunity for pedagogy experts to shape debate, pedagogy and practice

553 around DigiTech in HPE, rather than allowing technology experts to claim the

554 territory.

555 


\section{References}

Apple, M.W. (2006). Educating the "right” way: markets, standards, good, and inequality. New York, NY: Routledge.

Apple, M.W. (2007) Ideological success, educational failure? On the politics of the no child left behind. Journal of Teacher Education, 58(2), 108-116.

Armour, K. M. (Ed.). (2011). Sport pedagogy: An introduction for coaching and teaching sport. Harlow: Prentice Hall.

Armour, K.M. (2014) (Ed). Pedagogical Cases in Physical Education and Youth Sport. Oxon: Routledge.

Armour, K., Quennerstedt, M., Chambers, F. \& Makopoulou, K. (2015): What is ‘effective’ CPD for contemporary physical education teachers? A Deweyan framework, Sport, Education and Society, DOI:

$$
\text { 10.1080/13573322.2015.1083000 }
$$

Armour, K., Evans, G., Bridge, M., Griffiths, M., \& Lucas, S. (2016). Gareth: The beauty of the ipad for revolutionising learning in physical education. In A. Casey, V.A. Goodyear, \& K.M. Armour (Eds.) Digital technologies and learning in physical education: Pedagogical cases (pp. 213-230). London; Routledge.

Casey, A. (2014). Should we have a pedagogy of technology for physical education? Paper presented at the American Educational Research Association's Annual Meeting, Philadelphia, 3-7 April 2014.

Casey, A., Goodyear, V.A., \& Armour, K.M. (2016) Digital technologies and learning in physical education: Pedagogical cases. London; Routledge.

Chambers, F.C., Sherry, J., Murphy, O., O’Brien, W., \& Brelin, G. (2016). James: Physical education teacher. In A. Casey, V.A. Goodyear, \& K.M. Armour 
(Eds.) Digital technologies and learning in physical education: Pedagogical cases (pp. 49-68). London; Routledge.

Cordingly, P., Higgins, S., Greany, T., Buckler, N., Coles-Jordan, D., Crisp, B., Saunders, L., \& Coe, R. (2015). Developing great teaching: lessons from the international reviews into effective professional development. London, UK: Teacher Development Trust.

Clark, C.M. (1995). Thoughtful teaching. New York, NY: Teachers College Press

Dinham, S. (2013). Connecting clinical teaching practice with instructional leadership. Australian Journal of Education, 57, 225-236.

DCMS (2015). A new strategy for sport: consultation paper. UK; DCMS.

Dron, J. (2102). The Pedagogical-technological Divide and the Elephant in the Room. International Journal on E-Learning, 11(1), pp. 23-38.

Enright, E., Robinson, J., Hogan, A., Stylianou, M., Hay, J., Smith, F. \& Ball, A. (2016). Jarrod: The promise and messy realities of digital technology in physical education. In A. Casey, V.A.Goodyear, \& K.M. Armour (Eds.) Digital technologies and learning in physical education: Pedagogical cases (pp. 173-190). London; Routledge.

Evans, J. (2013) Physical Education as porn!, Physical Education and Sport Pedagogy, 18:1, 75-89, DOI: 10.1080/17408989.2011.631002

Fletcher, T., Vasily, A., Bullock, S.M., Kosnik, C., \& Ní Chróinín, D. (2016). Andy: Blogging with students - educational visions and digital realities. In A. Casey, V.A. Goodyear, \& K.M. Armour (Eds.) Digital technologies and learning in physical education: Pedagogical cases (pp. 104-120). London; Routledge. Fullan, M. (2013a). Stratosphere: Integrating technology, pedagogy, and change knowledge. Toronto, Ontario: Pearson. 
606 Fullan, M. (2013b). The new pedagogy: Students and teachers as learning partners. Learning Landscape, 6, 23-29.

608

609

610

Gard, M. (2014). eHPE: A history of the future. Sport Education and Society, 219 (6), 827-845.

Goodyear, V., Blain, D., Quarmby, T.\& Wainwright, N (2016). Dylan: The use of 'mobile’ ‘apps’ within a tactical inquiry approach. In A. Casey, V.A. Goodyear, \& K.M. Armour (Eds.) Digital technologies and learning in physical education: Pedagogical cases (pp. 13-30). London; Routledge.

Gleedie, D., Feith, J. Howe, P.D., Larsson, H., Cale, L. \& Casey, A. (2016). Joey: Social media as a tool for professional development. In A. Casey, V.A. Goodyear, \& K.M. Armour (Eds.) Digital technologies and learning in physical education: Pedagogical cases (pp. 121-136). London; Routledge.

Greenhow, C. and Lewin, C. (2016). Social media and education: reconceptualizing the boundaries of formal and informal learning. Learning, Media and Technology, 41(4), pp.6-30.

Halford, S. (2016, March). The Ethical Disruptions of Social Media Research: tales from the field. Paper presented at the Social Media \& Social Science Research Ethics conference, London, UK.

Hargreaves, A., \& Fullan, M. (2012). Professional capital: transforming teaching in every school. New York: Teachers College Press.

Hastie, P.A., Casey, A., \& Tarter, A-M (2010). A case study of wikis and student designed games in physical education. Technology, Pedagogy and Education, 19 (1), 79-91.

Hattie, J. (2012). Visible learning for teachers: Maximizing impact on learning. London, UK: Routledge. 
631

Hattie, J. (2009) Visible learning: a synthesis of over 800 meta-analyses relating to achievement. Oxon: Routledge.

Howard, S.K. \& Mozejko, A. (2015). Teachers: Technology, change and resistance In M. Henderson and G. Romeo (eds), Teaching and Digital Technologies: Big Issues and Critical Questions , Cambridge University Press. pp. 307-317).

Jones, E., Schupbach, R., Harvey, S. Bulger, S., \& Voelker, D. (2016). Rick: 'Energize and educate at every age’ - technology integration over a teaching career. In A. Casey, V.A. Goodyear, \& K.M. Armour (Eds.) Digital technologies and learning in physical education: Pedagogical cases (pp. 154172). London; Routledge.

Kerner, C. (2013). Relationships between body image, motivation and physical education (PE) experiences in 13-14 year old boys and girls. Unpublished $\mathrm{PhD}$ thesis: University of Bedfordshire.

Kirk, D. (2010). Physical education futures. London: Routledge.

Kong, S.C., Chan, T-W., Griffin, P., Hoppe, U., Huang, R., Kinshuk, Looi, C.K., et al. (2014). E-learning in school education in the coming 10 years for developing $21^{\text {st }}$ century skills’ critical research issues and policy implications. Educational Technology and Society, 17(1), 70-78.

Kretschmann, R. (2015). Physical education teachers’ subjective theories about integrating information and communication (ICT) into physical education. The Turkish Online Journal of Educational Technology, 14, (1), 68-96.

Leatherdale, S.T., Brown, S.K., Carson, V., Childs, R.A., Dubin, J.A., Elliott, S.J., Faulkner, G., et al., (2014). The COMPASS study: a longitudinal hierarchical research platform for evaluating natural experiments related to changes in 

Health, 14, 331.

657 Lenhart, A. (2015). Teens, social media and technology. Pew Research Centre.

Available at: http://www.pewinternet.org/files/2015/04/PI_TeensandTech_Update2015_040 9151.pdf

Luguetti, C., Oliver, K.L., Kirk, D., \& Dantas, L. (2015). Exploring an activist approach of working with boys from socially venerable backgrounds in a sport context. Sport, Education \& Society, iFirst

Lupton, D. (2014, August). Self-tracking modes: Reflexive self-monitoring and data practices. Paper presented at the Imminent Citizenships: Personhood and Identity Politics in the Informatic Age, Canberra. Retrieved from http://ssrn.com/abstract=2483549

Lupton, D. (2015). Data assemblages, sentient schools and digitized health and physical education (response to Gard). Sport, Education and Society, 20(1), $122-132$.

McKenzie, T.L. \& Lounsbery, M.A.F. (2013). Physical Education Teacher Effectiveness in a Public Health Context, Research Quarterly for Exercise and Sport, 84:4, 419-430, DOI: 10.1080/02701367.2013.844025

Miguel, C. (2016). Virtual intimacy on social media: from selfies to the coconstruction of intimacies through shared pictures. Social Media + Society, April-June, 1-10.

Palao, J.M., Hastie, P.A. and Guerrero, P. (2015). The impact of video technology on student performance in physical education. Technology, Pedagogy and Education, 24(1), pp. 51-63. 
Parker, M, \& Patton, K. (In Press). What Research Tells Us about Effective Continuing Professional Development for Physical Education Teachers. In: Ennis CD (ed) Routledge Handbook of Physical Education. Routledge: London.

Penney, D. \& Chandler, T. (2000). Physical Education: What Future(s)?, Sport, Education and Society, 5:1, 71-87, DOI: 10.1080/135733200114442

Quennerstedt, M., Öhman, M., Eriksson, C. (2008). Physical education in Sweden - a national evaluation. Education-line, 1-17.

Quennerstedt, M., Gibbs, B., Almqvist, J., Nilsson, J. \& Winther, H. (2016) Béatrice: Dance video games as a resource for teaching dance. In A. Casey, V.A. Goodyear, \& K.M. Armour (Eds.) Digital technologies and learning in physical education: Pedagogical cases (pp. 69-85). London; Routledge.

Rich, E. and Miah, A. (2014). Understanding digital health as public pedagogy: a critical framework. Societies, 4(2), pp.296-315.

Rich, E. and Miah, A. (2016): Mobile, wearable and ingestible health technologies: towards a critical research agenda, Health Sociology Review, DOI:10.1080/14461242.2016.1211486

Öhman, M., Almqvist, J., Meckbach, J., \& Quennerstedt, M. (2014). Competing for ideal bodies: a study of exergames used as teaching aids in schools. Critical Public Health, 24(2), pp.196-209

O’Sullivan, M. (2013). New directions, new questions: relationships between curriculum, pedagogy, and assessment in physical education, Sport, Education and Society, 18:1, 1-5, DOI: 10.1080/13573322.2012.719868 
Reid, C. (2009) Technology-loving Luddites? Declining participation in high school computing studies in Australia, British Journal of Sociology of Education, 30:3, 289-302, DOI: 10.1080/01425690902812562

Robinson, K. (2011). Out of our minds: learning to be creative. Chichester, UK: Capstone Publishing ltd.

Rosen, L. (2010). Rewired: Understanding the iGeneration and the way they learn. New York, NY: Palgrave MacMillan.

Sandaña, J. (2014). Blue-collar qualitative research: a rant. Qualitative Inquiry, 1-5.

Selwyn, N. (2002) Telling tales on technology: the ethical dilemmas of critically researching educational computing. Ashgate Press, Farnham, Surrey. ISBN $978-0-7546-1350-3$

Selwyn, N. (2014). Distrusting educational technology: critical questions for changing times. London: Routledge.

Selwyn, N. (2015). Minding our language: why education and technology is full of bullshit ... and what might be done about it, Learning, Media and Technology, DOI: 10.1080/17439884.2015.101252.

Selwyn, N., \& Stirling, E. (2016). Social media and education...now the dust has settled. Learning, Media \& Technology, 41(1), 1-5.

Sinelnikov, O.A. (2013). Using the iPad in a sport education season. Journal of Physical Education, Recreation and Dance, 83(1), 39-45.

Sipila, K. (2014). Educational use of information and communication technology: teachers’ perspective. Technology, Pedagogy, and Education, 23(2), 225-241.

Taranto, G., Dalbon, M., \& Gaetano, J. (2011). Academic social networking beings web 2.0 technologies to the middle grades. Middle School Journal, 42(5), 1219. 
728 Warfield, K., Cambre, C., \& Abidin, C. (2016). Introduction to the social media + 729 society special issue on selfies: me-diated inter-faces. Social Media + Society, 730 April-June, 1-5.

731 Webster, F., and K. Robins. (1986). Information technology: A Luddite analysis.

732 Norwood, NJ: Ablex Publishing Corporation.

733 Williamson, B. (2015) Algorithmic skin: health-tracking technologies, personal 734 analytics and the biopedagogies of digitized health and physical education. 735 Sport, Education and Society, 20(1), pp. 133-151, DOI:

736 Veletsianos, G. (2016). Emergence and innovation in digital learning: foundations 737 and applications. AU Press; Athabasca University, CA.

738 Vrasidas, C. (2015). The rhetoric of reform and teachers' use of ICT. British Journal 739 of Educational Technology, 46(2), 370-380. 